\title{
Validity and reliability of a bilateral assessment of locomotor skills in children
}

\author{
Franjo Lovric ${ }^{1}$, Igor Jelaska ${ }^{2}$, Cain C. T. Clark ${ }^{3, *}$, Michael Duncan ${ }^{3}$, and Durdica Miletic ${ }^{2}$ \\ ${ }^{1}$ Faculty of Science and Education, University of Mostar, Mostar, Bosnia and Herzegovina; ${ }^{2}$ Faculty of Kinesiology, Uni- \\ versity of Split, Split, Croatia; and ${ }^{3}$ Faculty of Health and Life Sciences, Coventry University, Coventry, United Kingdom
}

Copyright: (C) 2019 F. Lovric et al. This is an open access article licensed under the Creative Commons Attribution License (https://creativecommons.org/licenses/by/4.0/).

\begin{abstract}
Background: There is a paucity of empirical research on motor asymmetry in healthy children using currently available assessments. Objective: This study sought to develop bilateral tests for quantitative and qualitative assessment of locomotor skills in typically developing children and assess their validity and reliability. Methods: A sample of 78 children ( 35 girls, age $7.34 \pm 0.53$ years) underwent testing using three newly constructed bilateral tests: side rolling, single leg skips and single leg hops. Results: Between-subject reliability (Cronbach alpha: .97 to $.98, .98$ to $.99, .98$ to .99 , respectively), within-subject reliability (coefficient of variation: .04 to $.10, .05$ to $.11, .07$ to .13 , respectively), and between-rater reliability (intraclass correlation coefficient: .81 to $.92, .79$ to .94 , and .83 to .91 , respectively), of all three tests were found to be very high. Further, considering laterality, the results indicate very high construct validity (explained variance by single-extracted factor ranged from 94.48 to 96.68 , from 97.56 to 98.57 , and from 96.53 to 98.09, respectively). Conclusions: The results suggest that the newly constructed tests can be implemented as a reliable and valid tool for the assessment of bilateral locomotor skills in children.
\end{abstract}

Keywords: reliability, validity, fundamental motor skills, motor asymmetry

\section{Introduction}

Fundamental motor skills (FMS) are common to all individuals in all cultures of the world and are considered the building blocks for all complex movements, from everyday physical activity to specific sports skills, throughout the life course (Gallahue, Ozmun, \& Goodway, 2012). The most preponderant classification of FMS refers to two categories, i.e., locomotor skills and manipulative skills (Haywood \& Getchell, 2009; Holfelder \& Schott, 2014). Locomotor skills include movement of the body in space and imply running, hopping, jumping, skipping, galloping, sliding and leaping (Kirk \& Rhodes, 2011; Stodden et al., 2008). The period of life from two to seven years of age is as asserted to be the period of the greatest FMS development (Gallahue et al., 2012), and can be divided into three phases: initial, basic and mature (Lloyd \& Oliver, 2012). When beginning to participate in formal educational processes, i.e., while attending the lower grades of elementary school, pupils should be in the FMS mature phase of development. This phase of development is characterized by

\footnotetext{
* Address for correspondence: Cain C. T. Clark, Faculty of Health and Life Sciences, Coventry University, CV1 5FB, Coventry, United Kingdom. E-mail: cain.clark@coventry.ac.uk
}

integration of all components of adopted motor skills into coordinated, accurate and efficient performance (Goodway, Robinson, \& Crowe, 2010). Individuals that do not reach the mature stage in FMS development are shown to have a limited ability to progress in the acquisition of specific motor skills (Lagendorfer, Roberton, \& Stodden, 2011). Performance of FMS can be assessed with several reliable and valid tools; where the choice of test will depend on the context in which the assessment is planned (Clark, Moran, Drury, Venetsanou, \& Fernandes, 2018; Cools, De Martelaer, Samaey, \& Andries, 2009). Concomitantly, tests of motor skill assessment can be quantitative and/ or qualitative. Quantitative tests relate to the measurement of performance results and their advantage is the provision of a high level of reliability (Sporiš, Štimec, Milanović, \& Trajković, 2011). Conversely, qualitative assessment provides a systematic monitoring tool and an introspective human movement quality assessment that can be used to provide the most appropriate interventions for improving performance (Clark et al., 2017; Payne \& Isaacs, 2011). Because of the greater complexity of expression and the number of components being measured, the qualitative approach for measurement increases the discrepancy among the measurers and reduces reliability, however, the information obtained 
by measuring may possess a greater value (Lovrić, Jelaska, \& Bilić, 2015; Zuvela, Kezic, \& Krstulovic, 2016).

The selection of a qualitative or quantitative model of testing depends on the basic study objective, but the effects of transformation procedures should also be followed by a qualitative assessment of FMS, as it will be easier to identify which components of FMS should be facilitated, importantly; quantitative tools often report the outcome or product of the movement whereas qualitative are often more focused on the way the movement is performed or the process of the movement, and therefore, type of assessment must be carefully considered. Motor performance assessment according to topological regions of the body is based on a qualitative approach (Ulrich, 2000), which is especially recommended for the assessment of motor skills in younger age groups. Recently developed tools for FMS estimation include, the Movement Assessment Battery for Children (Movement-ABC; Henderson, Sugden, \& Barnett, 2007); Body Coordination Test for Children (KTK; Kiphard \& Schilling, 2007); and POLYGON (Zuvela, Bozanic, \& Miletic, 2011), but are not specifically designed to measure bilateral discrepancies.

Furthermore, bilateral motor coordination, or the ability to control such ipsilateral and contralateral movements, plays an important role in many, if not all, sporting disciplines (Akpinar, 2015). Bilateral motor coordination refers to the ability to use both sides of the body in an integrated and skilful manner (Williams, 1983). Ayres (1972) asserted that the process of integration of vestibular and proprioceptive sensations and the efficiency of inter-hemispheric connections are the bases for good bilateral integration of both sides of the body. The development of bilateral motor coordination begins early in life and is the basis for further motor development (Berk \& DeGangi, 1983; Kauffman, 1983). Furthermore, van der Fels et al. (2015) assert that bilateral body co-ordination is strongly related to cognitive ability, because they require greater cognitive processing than gross motor skills alone. However, there is a paucity of empirical research on motor asymmetry in healthy children using currently available FMS assessments (Cools et al., 2009). Therefore, the aim of this study was to develop and examine the psychometric characteristics (i.e., reliability and validity) of bilateral locomotor FMS assessment tests in children.

\section{Methods}

\section{Participants}

The sample included 78 children ( 35 girls, 43 boys) with an average age of $7.34 \pm 0.53$ years (range 6-8 years), all from the same geographical location (Mostar, Bosnia and Herzegovina), recruited using convenience sampling. Parents/guardians signed informed consent forms, whilst children signed informed assent. The entire research protocol was conducted in accordance with the Helsinki Declaration, and was conducted following the approval of the institutional ethics committee. The sample only included participants, who reported during anamnesis questioning, that had no known motor or neurological disturbances or injuries (3 participants were excluded), and who were not engaged in additional sporting activities, except in physical education classes (16 participants were excluded). Thus, from 97 potential participants, 78 were enrolled.

\section{Procedures}

Three bilateral tests for the assessment of locomotor FMS were constructed: side rolling (Table 1), single leg skips (Table 2) and single leg hops (Table 3). A model of error assessment was applied during motor performance according to the segment of knowledge (Ulrich, 2000), which is recommended for the assessment of motor skills in younger age groups. The performance of each skill was divided into three topological segments (side rolling, single leg skips, single leg hops) and, for each segment, evaluation criteria were identified and the evaluation scale $(2$ = correct, 1 = partly correct, $0=$ incorrect performance) was applied. A quantitative assessment was performed in relation to the presumed normal distribution (4 points for the top 20\% results, 3 points for the next $20 \%$ of results, ..., 0 points for the bottom $20 \%$ of results). An overall score was attained by summing all individual performances. The aforementioned procedure combined qualitative and score ranking assessment, but it also provided the possibility to inspect each of them individually. An assessment was carried out by three independent experts (accredited kinesiologists). The average value of all three expert's scores was taken as the participant's score. Description of the newly constructed tests are detailed in Table 4.

\section{Description of experimental settings}

All measurements were conducted in the school gymnasium, under the same conditions, in the morning. During measurements, based on parental/guardian observations, it was concluded that all participants were in good health. Measurements took place over three successive days and during single measurement 
Table 1

Side rolling - scoring

\begin{tabular}{lc}
\hline Observation & Score \\
\hline Participant is performing test linearly and smoothly & 2 \\
Participant deviates from a linear/straight line movement, but completes the task & 1 \\
Linear motion path is visibly deteriorated & 0 \\
\hline Participant performs the task at the same pace, and continuously & 2 \\
Participant's pace and continuity of performance is inconsistent & 1 \\
The pace and continuity of the performance is visibly deteriorated & 0 \\
\hline Participant performs task with arms and torso stretched & 2 \\
Participant, while performing, does not maintain hands and body throughout the whole performance & 1 \\
Participant significantly distorts the position of hands and the body (helping rotation with the hands) & 0 \\
\hline Participant performs the whole task with their legs stretched & 2 \\
Participant maintains position of the legs for most of the task & 1 \\
Participant significantly distorts the position of legs (helping rotation with the legs) & 0 \\
\hline First 20\% of the best results & 4 \\
Second 20\% of the best results & 3 \\
Third 20\% of the best results & 2 \\
Fourth 20\% of the best results & 1 \\
Other 20\% of the results & 0 \\
\hline
\end{tabular}

Table 2

Single leg skips - scoring

\begin{tabular}{lc}
\hline Observation & Score \\
\hline During performance, arms of the participant are bent in the elbows and are operating circular movements & 2 \\
During performance, arms are bent in the elbows, and movement up and down is visible & 1 \\
During performance arms are to the body & 0 \\
\hline Participant performs the task at the same pace and continuously in all six jumps & 2 \\
Participant's pace and continuity of performance is inconsistent & 1 \\
The pace and continuity of the performance is visibly deteriorated & 0 \\
\hline Participant performs the task in a balanced position, with their alternate leg bent at 90 degrees & 2 \\
Participant performs the task, but sways to maintain balance & 1 \\
Participant loses their balance during the performance and steps with the free leg on the ground & 0 \\
\hline Participant performs the task with only one foot on the ground & 2 \\
Participant performs the task with one foot on the ground (more than three jumps, but less than six) & 1 \\
Participant does not successfully perform the task & 0 \\
\hline First 20\% of the best results & 4 \\
Second 20\% of the best results & 3 \\
Third 20\% of the best results & 2 \\
Fourth 20\% of the best results & 1 \\
Other 20\% of the results & 0 \\
\hline
\end{tabular}


Table 3

Single leg hops - scoring

\begin{tabular}{lc}
\hline Observation & Score \\
\hline Participant performs the task within the marked area & 2 \\
Participant leaves the marked area during hops (up to 3 times) & 1 \\
Participant leaves the marked area during hops (more than 3 times) & 0 \\
\hline Participant performs the task at the same pace and continuously in all six jumps & 2 \\
Participant's pace and continuity of performance is inconsistent & 1 \\
The pace and continuity of the performance is visibly deteriorated & 0 \\
\hline Participant performs the task in a balanced position, with their alternate leg bent 90 degrees & 2 \\
Participant performs the task, but sways to maintain balance & 1 \\
The position of body, arms and free leg during performance is visibly deteriorated & 0 \\
\hline Participant performs the task with one foot on the ground & 2 \\
Participant performs the task with one foot on the ground (more than three jumps, but less than six) & 1 \\
Participant does not successfully perform the task & 0 \\
\hline First 20\% of the best results & 4 \\
Second 20\% of the best results & 3 \\
Third 20\% of the best results & 2 \\
Fourth 20\% of the best results & 1 \\
Other 20\% of the results & 0 \\
\hline
\end{tabular}

Table 4

Comprehensive test battery details

\begin{tabular}{|c|c|c|c|}
\hline & Side rolling (right and left) & Single leg skips (right and left) & Single leg hops (right and left) \\
\hline Place & School gym & School gym & School gym \\
\hline Equipment & $\begin{array}{l}\text { Three or four mats joined } \\
\text { lengthways }\end{array}$ & $\begin{array}{l}\text { Obstacle } 1 \mathrm{~m} \text { long, } 8 \mathrm{~cm} \text { high and } \\
5 \mathrm{~cm} \text { wide }\end{array}$ & Adhesive tape \\
\hline Start position & $\begin{array}{l}\text { The participant lies on their abdo- } \\
\text { men with their arms next to } \\
\text { their body, lengthways on the } \\
\text { edge of the mat. }\end{array}$ & $\begin{array}{l}\text { The participant stands on the } \\
\text { right leg laterally in relation to } \\
\text { the obstacle, the left leg bent } \\
90 \text { degrees at the knee, arms } \\
\text { beside the body. }\end{array}$ & $\begin{array}{l}\text { The participant stands on their } \\
\text { right leg, with the left leg bent } \\
90 \text { degrees at the knee, their } \\
\text { arms beside the body. In front } \\
\text { of the participant there are six } \\
\text { marked fields }(30 \mathrm{~cm} \times 30 \mathrm{~cm}) \\
\text { placed in a zigzag formation. }\end{array}$ \\
\hline Procedure & $\begin{array}{l}\text { When signalled, the participant } \\
\text { starts side rolling to the right. } \\
\text { The task is to travel } 3 \mathrm{~m} \text { in the } \\
\text { shortest time. The participant } \\
\text { then gets up, briefly rests and } \\
\text { returns to the starting position. } \\
\text { When signalled, the participant } \\
\text { starts side rolling to the left. }\end{array}$ & $\begin{array}{l}\text { When signalled, the participant, } \\
\text { in the shortest possible time, } \\
\text { performs six one-legged lateral } \\
\text { jumps over the obstacle. Repeat } \\
\text { the test with left leg. }\end{array}$ & $\begin{array}{l}\text { When signalled, the participant } \\
\text { performs single-legged hops } \\
\text { into the marked fields which } \\
\text { are in front of them. The task } \\
\text { is to perform single leg hops } \\
\text { into each of the marked areas. } \\
\text { Repeat the task with the other } \\
\text { leg. }\end{array}$ \\
\hline Administration time & 3 minutes & 5 minutes & 5 minutes \\
\hline
\end{tabular}


day, participants were measured three times in one test, firstly at the right side than on the left side. Participant's trials were recorded by digital camera (HCV770K Full HD Camcorder, 1080p, 20× digital zoom; Panasonic, Osaka, Japan) and after all recordings were collected, three expert judges rated all performances using a process-oriented checklist for each exercise (see Tables 1-3).

\section{Data processing methods}

The following descriptive statistics were calculated: arithmetic mean, standard deviation, minimum and maximum. The Kolmogorov-Smirnov test was used to examine the normality of distribution, and the data were confirmed to be normally distributed, and corroborated following assessment of skewness $\left(\alpha_{3}\right)$ and kurtosis $\left(\alpha_{4}\right)$. Factor analysis investigated the construct validity of judges' performance assessments based on the specified criteria and determined a factor structure of judges' ratings. The correlation coefficients of the extracted factor with ratings of individual judge (the factor structure matrix), and the absolute and relative amount of variability of judges' ratings due to extracted factor has been presented. Cronbach alpha coefficient $(\mathrm{C} \alpha$, between-subject reliability), coefficient of variation $(\mathrm{CV}$, within subject reliability), together with intraclass correlation coefficient (ICC, between-rater reliability) and average correlation among judges' ratings (IIR, between-rater reliability) were calculated; coefficient for C $\alpha$, ICC and IIR were reported according to Nunnally and Bernstein (1994), where, $<.5$ is unacceptable, $\geq .5$ but $<.6$ is poor, $\geq .6$ but $<.7$ is questionable, $\geq .7$ but $<.8$ is acceptable, $\geq .8$ but $<.9$ is good, and $\geq .9$ is excellent. All data has been processed by using data analysis software Statistica (Version 13; Dell, Round Rock, TX, USA). For all tests, alpha was set, a priori, at $p \leq .05$.

\section{Results}

Excellent between-subject reliability was identified through high and stable $\mathrm{C} \alpha$ coefficients, while relatively small CV indicated appropriate within-subject reliability for all tests (Tables 5-7). High values of IIR, as well as ICC, both left and right sides are suggestive of excellent between-rater reliability. Furthermore, extraction of a single factor with a high percentage of explained variability was evident, with a score of more than $94 \%$ in all the tests.

Table 5

Reliability and validity of constructed test: Rolling into right and left side at three measurement points

\begin{tabular}{|c|c|c|c|c|c|c|}
\hline & \multicolumn{3}{|c|}{ Right side } & \multicolumn{3}{|c|}{ Left side } \\
\hline & 1 st measurement & 2nd measurement & 3rd measurement & 1st measurement & 2nd measurement & 3rd measurement \\
\hline $\mathrm{C} \alpha$ & & .97 & & & .98 & \\
\hline $\mathrm{CV}$ & & .04 & & & .10 & \\
\hline ICC & .85 & .81 & .92 & .88 & .85 & .86 \\
\hline IIR & .94 & .94 & .93 & .95 & .92 & .93 \\
\hline $\mathrm{S} 1$ & -.98 & -.98 & -.98 & -.98 & -.97 & -.97 \\
\hline S2 & -.97 & -.98 & -.98 & -.98 & -.97 & -.97 \\
\hline S3 & -.98 & -.98 & -.97 & -.99 & -.97 & -.98 \\
\hline Var & 2.88 & 2.89 & 2.85 & 2.90 & 2.83 & 2.85 \\
\hline V\% & 96.02 & 96.22 & 95.16 & 96.68 & 94.48 & 95.08 \\
\hline $\mathrm{KS}-p$ & $>.20$ & $>.20$ & $>.20$ & $>.20$ & $<.15$ & $<.20$ \\
\hline$M$ & 5.65 & 5.73 & 5.64 & 4.94 & 5.27 & 5.37 \\
\hline$\sigma$ & 2.36 & 2.27 & 2.14 & 2.33 & 2.03 & 1.95 \\
\hline Min & 1.33 & 0.00 & 1.00 & 0.00 & 0.00 & 1.00 \\
\hline Max & 11.00 & 10.00 & 11.00 & 10.67 & 10.33 & 9.67 \\
\hline$\alpha_{3}$ & 0.01 & -0.30 & -0.14 & -0.19 & -0.15 & -0.10 \\
\hline$\alpha_{4}$ & 0.65 & -0.35 & -0.23 & -0.14 & 0.32 & -0.36 \\
\hline
\end{tabular}

Note. $\mathrm{C} \alpha=$ Cronbach alpha coefficient; $\mathrm{CV}=$ coefficient of variation; $\mathrm{ICC}=$ intraclass correlation coefficient; IIR $=$ average correlation between expert judges ratings; S1, S2, S3 = factor structure matrix coefficients; Var = variance accounted for by the factor; V\% = proportion of variance accounted for by the factor; KS $-p=$ significance of Kolmogorov Smirnov test; $\sigma=$ standard deviation; Min $=$ minimum result; Max = maximum result; $\alpha_{3}=$ skewness; $\alpha_{4}=$ kurtosis. 
Table 6

Reliability and validity of constructed test: Right leg hops and left leg hops at three measurement points

\begin{tabular}{|c|c|c|c|c|c|c|}
\hline & \multicolumn{3}{|c|}{ Right leg } & \multicolumn{3}{|c|}{ Left leg } \\
\hline & 1st measurement & 2nd measurement & 3rd measurement & 1st measurement & 2nd measurement & 3rd measurement \\
\hline $\mathrm{C} \alpha$ & & .99 & & & .98 & \\
\hline $\mathrm{CV}$ & & .05 & & & .11 & \\
\hline ICC & .94 & .79 & .86 & .89 & .82 & .86 \\
\hline IIR & .97 & .97 & .97 & .98 & .98 & .98 \\
\hline $\mathrm{S} 1$ & -.99 & -.99 & -.98 & -.99 & -.99 & -.99 \\
\hline $\mathrm{S} 2$ & -.99 & -.99 & -.99 & -.99 & -.99 & -.99 \\
\hline S3 & -.99 & -.99 & -.99 & -.99 & -.99 & -.99 \\
\hline Var & 2.93 & 2.94 & 2.93 & 2.94 & 2.96 & 2.66 \\
\hline V\% & 97.73 & 97.90 & 97.56 & 98.32 & 98.57 & 98.51 \\
\hline $\mathrm{KS}-p$ & $>.20$ & $<.10$ & $<.15$ & $>.20$ & $<.10$ & $>.20$ \\
\hline$M$ & 6.19 & 7.12 & 7.20 & 5.34 & 6.48 & 6.61 \\
\hline$\sigma$ & 3.35 & 3.04 & 2.57 & 3.42 & 3.06 & 2.87 \\
\hline Min & 0.00 & 1.00 & 1.33 & 0.00 & 0.00 & 0.00 \\
\hline $\operatorname{Max}$ & 12.00 & 12.00 & 11.00 & 11.00 & 12.00 & 11.67 \\
\hline$\alpha_{3}$ & -0.12 & -0.44 & -0.48 & -0.08 & -0.27 & -0.38 \\
\hline$\alpha_{4}$ & -0.91 & -0.89 & -0.80 & -1.05 & -0.93 & -0.65 \\
\hline
\end{tabular}

Note. $\mathrm{C} \alpha=$ Cronbach alpha coefficient $\mathrm{CV}=$ coefficient of variation; $\mathrm{ICC}=$ intraclass correlation coefficient; $\mathrm{IIR}=$ average correlation between expert judges ratings; S1, S2, S3 = factor structure matrix coefficients; Var = variance accounted for by the factor; V\% $=$ proportion of variance accounted for by the factor; KS- $p=$ significance of Kolmogorov Smirnov test; $\sigma=$ standard deviation; Min $=$ minimum result; Max = maximum result; $\alpha_{3}=$ skewness; $\alpha_{4}=$ kurtosis.

Table 7

Reliability and validity of constructed test: Right leg skips and left leg skips at three measurement points

\begin{tabular}{|c|c|c|c|c|c|c|}
\hline & \multicolumn{3}{|c|}{ Right leg } & \multicolumn{3}{|c|}{ Left leg } \\
\hline & 1st measurement & 2nd measurement & 3rd measurement & 1 st measurement & 2nd measurement & 3rd measurement \\
\hline $\mathrm{C} \alpha$ & & .98 & & & .99 & \\
\hline $\mathrm{CV}$ & & .07 & & & .13 & \\
\hline ICC & .84 & .83 & .87 & .88 & .85 & .91 \\
\hline IIR & .95 & .97 & .95 & .96 & .96 & .96 \\
\hline S1 & -.98 & -.99 & -.98 & -.99 & -.98 & -.99 \\
\hline S2 & -.99 & -.99 & -.99 & -.99 & -.99 & -.99 \\
\hline S3 & -.99 & -.99 & -.99 & -.99 & -.98 & -.98 \\
\hline Var & 2.90 & 2.94 & 2.90 & 2.93 & 2.92 & 2.92 \\
\hline V\% & 96.83 & 98.09 & 96.53 & 97.51 & 97.33 & 97.42 \\
\hline $\mathrm{KS}-p$ & $>.20$ & $>.20$ & $>.20$ & $<.20$ & $>.20$ & $>.20$ \\
\hline M & 5.21 & 5.33 & 5.46 & 4.44 & 4.57 & 4.79 \\
\hline$\sigma$ & 3.37 & 3.46 & 3.33 & 3.01 & 3.25 & 3.22 \\
\hline Min & 0.00 & 0.00 & 0.00 & 0.00 & 0.00 & 0.00 \\
\hline $\operatorname{Max}$ & 11.67 & 12.00 & 11.00 & 12.00 & 12.00 & 11.00 \\
\hline$\alpha_{3}$ & 0.12 & 0.22 & 0.03 & 0.51 & 0.39 & 0.15 \\
\hline$\alpha_{4}$ & -1.03 & -0.96 & -1.03 & -0.41 & -0.68 & -1.01 \\
\hline
\end{tabular}

Note. $\mathrm{C} \alpha=$ Cronbach alpha coefficient $\mathrm{CV}=$ coefficient of variation; $\mathrm{ICC}=$ intraclass correlation coefficient; $\mathrm{IIR}=$ average correlation between expert judges ratings; S1, S2, S3 = factor structure matrix coefficients; Var = variance accounted for by the factor; V\% $=$ proportion of variance accounted for by the factor; KS- $p=$ significance of Kolmogorov Smirnov test; $\sigma=$ standard deviation; Min = minimum result; Max = maximum result; $\alpha_{3}=$ skewness; $\alpha_{4}=$ kurtosis. 


\section{Discussion}

The current study presents three novel motor competence tests for the assessment of locomotor FMS and the results provide evidence of the reliability and validity of these measures in children. The principal findings were that very high between-participant reliability was demonstrated through excellent $\mathrm{C} \alpha$ coefficient (for all tests .97-.99), while relatively small observed CV (for all tests .04-.13) indicates appropriate within-participant reliability for all tests. High values of IIR, as well as ICC, for both left and right sides indicate excellent between-rater reliability (across all tests IIR $=.92-.98$, $\mathrm{ICC}=.79-.94)$.

The high reliability attained in this study is comparable to the reliability results in more ubiquitous assessments of fundamental motor skills, such as the Test of Gross Motor Development, second edition (TGMD-2; Lopes, Saraiva, \& Rodrigues, 2018), where reliability coefficients for locomotor and manipulative motor skill tests in boys and girls were high and stable. Further, the psychometric properties of the TGMD-2 have been evaluated and the manual reports excellent testretest reliability and inter-rater reliability $(r>.85)$ as well as a good internal consistency $(\mathrm{C} \alpha=.85$ and .88 for locomotor and object control subtests, respectively; Kim, Han, \& Park, 2014; Valentini, 2012; Valentini, Ramalho, \& Oliveira, 2014). Although the TGMD-2 assess locomotor elements, it is important to note that our new tests focuses specifically on locomotor FMS, and demonstrated preferential reliability and higher internal consistency (Tables 5-7), and, conceivably, offers a novel insight into laterality in children's movement through measurement of both right and left sided movements, permitting a summative assessment (right and left), or individual side assessment (right or left). Notwithstanding, this should be interpreted with caution, as further studies are necessary to investigate the veracity and sensitivity of the bilateral assessments across age groups. Moreover, standard reference values need to be ascertained in order to enhance the usability of the newly created test battery.

Extraction of a single factor in all tests indicated satisfactory construct validity of the tests for both sides of the body, at all three measuring points (Chien, Brown, \& McDonald, 2010; Valentini et al., 2014). Reliability and validity indicators demonstrate the applicability of these tests (Longmuir et al., 2017), which, due to wellestablished evaluation criteria and quantitative components, enable quality assessment and insight into the locomotor skills of children. Evidently, a methodological base for further scientific research of factors that may affect the quality of performance of motor skills is well founded. The importance of this study is reflected in the fact that the newly constructed bilateral tests had satisfactory psychometric characteristics (i.e., reliability and validity), which were comparable to other ubiquitous motor competence test (Kim et al., 2014; Valentini, 2012; Valentini et al., 2014), which makes them potentially useful in further scientific research and practical use (Barnett et al., 2016; Clark \& Barnes, 2018). Additionally, it should be emphasized that, although the newly constructed tests are both qualitative and quantitative, the constructed methodology permits the evaluation of qualitative (performance technique) or quantitative (performance effectiveness) parameters independently, as well as concurrently. A prominent advantage of the constructed tests is the fact that they require very modest and simple materials and conditions for their performance and measurement, and require a minimal amount of time to complete, particularly in comparison to other, more pervasive assessments (Herrmann, Heim, \& Seelig, 2019). However, of note is that whilst we utilised an exploratory factor analysis, datasets comprised of larger sample sizes will be required in order to perform confirmatory analyses. Nevertheless, the current study presents a useful, conceptual, addition to the literature.

\section{Conclusion}

These newly constructed tests can be used in children for the bilateral assessment of locomotor skills, although this must be verified in further studies; moreover, given the promising psychometric properties, the assessment could be operationalized as an assessment tool of motor competence, to monitor longitudinal changes in overall and right vs, left scores, or in the evaluation of specific educational or training programmes.

\section{Conflict of interest}

There were no conflicts of interest.

\section{References}

Akpinar, S. (2015). The effect of long-term bimanual training on arm selection during reaching tasks. Kinesiology, 47, 226-235.

Ayres, A. J. (1972). Sensory integration and learning disorders. Los Angeles, CA: Western Psychological Services.

Barnett, L. M., Stodden, D., Cohen, K. E., Smith, J. J., Lubans, D., Lenoir, M., ... Morgan, P. J. (2016). Fundamental movement skills: An important focus. Journal of Teaching in Physical Education, 35, 219-225. 
Berk, R. A., \& DeGangi, G. A. (1983). DeGangi-Berk Test of Sensory Integration manual. Los Angeles, CA: Western Psychological Services.

Chien, C. W., Brown, T., \& McDonald, R. (2010). Examining content validity and reliability of the Assessment of Children's Hand Skills (ACHS): A preliminary study. American Journal of Occupational Therapy, 64, 756-767.

Clark, C. C. T., \& Barnes, C. M. (2018). Paediatric physical activity and health: Moving towards a measure of quality. Baltic Journal of Health and Physical Activity, 10(4), 7-24.

Clark, C. C. T., Barnes, C. M., Swindell, N. J., Holton, M. D., Bingham, D. D., Collings, P. J., ... Stratton, G. (2017). Profiling movement and gait quality characteristics in preschool children. Journal of Motor Behavior, 50, 557-565.

Clark, C. C. T., Moran, J., Drury, B., Venetsanou, F., \& Fernandes, J. (2018). Actual vs. perceived motor competence in children (8-10 years): An issue of non-veridicality. Journal of Functional Morphology and Kinesiology, 3, 20.

Cools, W., De Martelaer, K., Samaey, C., \& Andries, C. (2009). Movement skill assessment of typically developing preschool children: A review of seven movement skill assessment tools. Journal of Sports Science and Medicine, 8, 154-168.

Gallahue, D. L., Ozmun, J. C., \& Goodway, J. D. (2012). Understanding motor development: Infants, children, adolescents, adults (7th ed.). New York, NY: McGraw-Hill.

Goodway, J. D., Robinson, L. E., \& Crowe, H. (2010). Gender differences in fundamental motor skill development in disadvantaged preschoolers from two geographical regions. Research Quarterly for Exercise and Sport, 81, 17-24.

Haywood, K. M., \& Getchell, N. (2009). Life span motor development (5th ed.). Champaign, IL: Human Kinetics.

Henderson, S. E., Sugden, D. A., \& Barnett, A. L. (2007). Movement Assessment Battery for children - 2 Examiner's Manual. London, United Kingdom: Harcourt Assessment.

Herrmann, C., Heim, C., \& Seelig, H. (2019). Construct and correlates of basic motor competencies in primary school-aged children. Journal of Sport and Health Science, 8, 63-70.

Holfelder, B., \& Schott, N. (2014). Relationship of fundamental movement skills and physical activity in children and adolescents: A systematic review. Psychology of Sport and Exercise, 15, 382-391.

Kauffman, N. A. (1983). Occupational therapy with children - The school selling. In H. L. Hopkins \& H. D. Smith (Eds.), Willard and Spackman's occupational therapy (6th ed., pp. 683-719). Philadelphia, PA: J. B. Lippincott.

Kim, C.-I., Han, D.-W., \& Park, I.-H. (2014). Reliability and validity of the Test of Gross Motor Development-II in Korean preschool children. Research in Developmental Disabilities, 35, 800-807.

Kiphard, E. J., \& Schilling, F. (2007). Körperkoordinationtest für Kinder (2nd revised and supplemented ed.). Weinheim, Germany: Beltz test.

Kirk, M. A., \& Rhodes, R. E. (2011). Motor skill interventions to improve fundamental movement skills of preschoolers with developmental delay. Adapted Physical Activity Quarterly, 28, 210-232.

Langendorfer, S. J., Roberton, M. A., \& Stodden, D. F. (2011). Biomechanical aspects of the development of object projection skills. In M. De Ste Croix \& T. Korff
(Eds.), Paediatric biomechanics and motor control: Theory and application (pp. 180-206). Oxford, United Kingdom: Routledge.

Lloyd, R. S., \& Oliver, J. L. (2012). The youth physical development model: A new approach to long-term athletic development. Strength and Conditioning Journal, 34, 61-72.

Longmuir, P. E., Boyer, C., Lloyd, M., Borghese, M. M., Knight, E., Saunders, T. J., ... Tremblay, M. S. (2017). Canadian Agility and Movement Skill Assessment (CAMSA): Validity, objectivity, and reliability evidence for children 8-12 years of age. Journal of Sport and Health Science, 6, 231-240.

Lopes, V. P., Saraiva, L., \& Rodrigues, L. P. (2018). Reliability and construct validity of the test of gross motor development-2 in Portuguese children. International Journal of Sport and Exercise Psychology, 16, 250-260.

Lovrić, F., Jelaska, I., \& Bilić, Ž. (2015). Obstacle polygon as an assessment of fundamental movement skills in 6-yearold children. Croatian Journal of Education, 17, 213-225.

Nunnally, J., \& Bernstein, L. (1994). Psychometric theory. New York, NY: McGraw-Hill Higher.

Payne, V. G., \& Isaacs, L. D. (2011). Human motor development: A lifespan approach (8th ed.) New York, NY: McGraw Hill.

Smits-Engelsman, B. C., Fiers, M. J., Henderson, S. E., \& Henderson, L. (2008). Interrater reliability of the Movement Assessment Battery for Children. Physical Therapy, 88, 286-294.

Sporiš, G., Štimec, D., Milanović, Z., \& Trajković, N. (2011). Reliability and factorial validity of the cycling tests among school population. Acta Kinesiologica, 5(2), 17-21.

Stodden, D. F., Goodway, J. D., Langendorfer, S. J., Roberton, M. A., Rudisill, M. E., Garcia, C., \& Garcia, L. E. (2008). A developmental perspective on the role of motor skill competence in physical activity: An emergent relationship. Quest, 60, 290-306.

Ulrich, D. A. (2000). Test of Gross Motor Development (2nd ed.) Austin, TX: Pro-Ed Publishers.

Valentini, N. (2012). Validity and reliability of the TGMD-2 for Brazilian children. Journal of Motor Behavior, 44, 275-280.

Valentini, N. C., Ramalho, M. H., \& Oliveira, M. A. (2014). Movement Assessment Battery for Children-2: Translation, reliability, and validity for Brazilian children. Research in Developmental Disabilities, 35, 733-740.

van der Fels, I., Wierke, S., Hartman, E., Elferink-Gemser, M., Smith, J., \& Visscher, C. (2015). The relationship between motor skills and cognitive skills in 4-16 year old typically developing children: A systematic review. Journal of Science and Medicine in Sport, 18, 697-703.

Williams, H. G. (1983). Perceptual and motor development. Englewood Cliffs, NJ: Prentice-Hall.

Zuvela, F., Bozanic, A., \& Miletic, D. (2011). POLYGON - A new fundamental movement skills test for 8 year old children: Construction and validation. Journal of Sports Science and Medicine, 10, 157-163.

Zuvela, F., Kezic, A., \& Krstulovic, S. (2016). Morphological and motor-functional factors influencing fundamental movement skills in eight-year-old children. Iranian Journal of Pediatrics, 26, e5709. 